\title{
Who cares and how much: exploring the determinants of co-residential informal care
}

\author{
Emmanouil Mentzakis • Paul McNamee • \\ Mandy Ryan
}

Published online: 10 March 2009

(C) Springer Science+Business Media, LLC 2009

\section{Erratum to: Rev Econ Household DOI 10.1007/s11150-008-9047-0}

In the original version of this article the acknowledgments were unfortunately omitted.

\section{Acknowledgments}

We would like to thank two anonymous reviewers and Michael Grossman for their valuable comments and suggestions. This work was carried out whilst Emmanouil Mentzakis was a PhD student at the University of Aberdeen, funded by an MRC capacity building studentship. Mandy Ryan and Paul McNamee are funded by the University of Aberdeen. Financial support from the Chief Scientist Office of the Scottish Government Health Directorate is also acknowledged. Data from the British Household Panel Survey (BHPS) were supplied by the ESRC Data Archive. The usual disclaimer applies.

The online version of the original article can be found under doi:10.1007/s11150-008-9047-0.

\section{E. Mentzakis $(\bowtie)$}

Department of Economics, McMaster University, 1280 Main St. West,

Hamilton, ON, Canada L8S 4M4

e-mail:mentzak@mcmaster.ca

P. McNamee · M. Ryan

Health Economics Research Unit, University of Aberdeen, Polwarth Building,

Foresterhill, Aberdeen AB25 2ZD, UK 